\title{
Las diferencias flexivas entre las lenguas polaca y casuba: los sustantivos masculinos y neutros
}

\author{
Almudena Moncada CAstellanos \\ Universidad del País Vasco (España) \\ amoncada95@gmail.com
}

Recibido: Octubre de 2011

Aceptado: Febrero de 2012

\section{Resumen}

En este estudio, analizamos la flexión nominal de los sustantivos masculinos y neutros en la lengua casuba. Hemos aplicado el método comparativo con los sistemas del eslavo común y del polaco a fin de ilustrar el origen de las desinencias que presenta el casubo en contraste con la lengua polaca. Esperamos que nuestro análisis diacrónico de la flexión casuba nos proporcione los mejores argumentos para identificar nuestra hipótesis acerca del origen del casubo, como lengua dotada de autonomía e identidad propias.

Palabras clave: Lingüística comparada, Evolución diacrónica, Flexión nominal, Casubo, Lengua polaca.

The morphological differences in the Polish and Cassubian Languages: masculine and neutral sustantives

\begin{abstract}
In this paper we analyze the nominal flexion of masculine and neutral cassubian sustantives. We examine the nominal flexion according to the stem and endings of each declension, comparing cassubian nominal systems with Old Slavic and Polish's systems. From this prospect we analyze the origin of cassubian endings, and we compare this endings of with the patterns of Polish language. We hope that our diachronic analysis of the cassubian flexion provide us arguments to demostrate our hypothesis about the origin of casubo, as language with autonomy and identity.
\end{abstract}

Key words: Comparative Linguistics, Diachronic Evolution, Nominal Declension, Cassubian Language, Polish Language.

SUMARIO: 1.Introducción; 2.Origen y formación de las declinaciones; 3.Los sustantivos masculinos: desinencias regulares; 4. Rasgos diferenciadores en la declinación de los sustantivos masculinos; 5.Los sustantivos neutros: desinencias regulares; 6.Rasgos diferenciadores en la declinación de los sustantivos neutros; 7.Conclusiones. 


\section{Introducción}

El proceso de formación de los sistemas flexivos en la lengua casuba está todavía pendiente de una investigación sistemática desde una perspectiva estrictamente diacrónica. Este trabajo pretende, en primer lugar, organizar el material de la morfología nominal que, a nuestro juicio, presenta una mayor relevancia a la hora de determinar el origen del casubo dentro del ámbito común de las lenguas eslavas. En consecuencia, hemos desarrollado una línea de evolución con el fin de dar respuesta a algunas de las cuestiones más complejas que suscita la reconstrucción morfológica desde la época del eslavo común. El enfoque histórico resulta, sin duda, novedoso con respecto a los estudios de esta lengua realizados hasta ahora, de carácter primordialmente sincrónico.

El estudio se limita a las modificaciones producidas en la morfología nominal casuba de impulso común en el ámbito eslavo. Para la época histórica, esto significa que son objeto de nuestro análisis únicamente aquellos procesos de cambio flexivo que encuentran su justificación lingüística en la comunidad de partida, el eslavo común. Por consiguiente, en este trabajo se describen los aspectos principales de la flexión nominal casuba desde la perspectiva de su estructuración en eslavo común. Así pues, presentamos nuestra interpretación conforme a los hechos lingüísticos observados. Para contrastar nuestras argumentaciones, recurrimos en muchas ocasiones al método comparativo, tomando como referencia la lengua polaca, por su relación de parentesco dentro del grupo lejítico ${ }^{1}$.

La estructura de la flexión nominal de la lengua casuba será analizada atendiendo específicamente al origen de las desinencias de los distintos tipos flexivos. Asumimos en este estudio la noción de macroclase flexiva (CARSTAIRS 1987: 69). Este concepto permite agrupar varias de las clases flexivas de las lenguas eslavas; en nuestro caso, la declinación masculina y neutra de los sustantivos, pues esta diferencia depende tan sólo de un criterio morfosemántico como es el género y, por tanto, externo a la flexión. De la misma manera, las clases animada e inanimada de los masculinos se encuentran dentro de la misma macroclase, dado que sus diferencias son predecibles a partir del rasgo semántico del subgénero. Por ello, también las clases palatalizada y no palatalizada, cuyas diferencias dependen de una alternancia fonológica, han de ser consideradas variantes de una misma macroclase flexiva.

\section{Origen y formación de las declinaciones}

La evolución de la mayoría de los sistemas eslavos en periodo histórico conduce a una reducción importante de la diversidad desinencial heredada del eslavo común. Varios tipos flexivos son eliminados integrándose en los modelos de otras clases flexivas más productivas conforme a un proceso de absorción ${ }^{2}$. La mayor parte de las

\footnotetext{
${ }^{1}$ Dentro del grupo de lenguas eslavas occidental, el grupo lejítico incluye el polaco, el casubo y el polabo.

2 Desaparición de uno o más tipos declinativos que acaban subsumiéndose en la clase flexiva dominante sin dejar rastro de su antigua naturaleza desinencial. Ej.: la absorción de los temas en $-\bar{u}$ por los temas en $-\bar{a}$; de los temas neutros en $-s$ por los temas neutros en $-o$.
} 
lenguas eslavas pasa a estar formada principalmente por tres macroclases flexivas:

1. La clase masc.-neutra de tema en consonante (a partir de la fusión ${ }^{3}$ de los temas en $-o \mathrm{y}-u)$.

Flexión unificada del eslavo común:

SINGULAR - Nominativo - $\varnothing$, Vocativo $-e /-u$, Acusativo $-\varnothing /-a$, Genitivo $-a /-u$, Dativo - $u$ /-owi, Instrumental -em, Locativo -e/-u. DUAL - Nom.Acu. - $a$, Gen. Loc. $-o w u$, Dat. Instr. -oma.

PLURAL - Nominativo -i, y / -owie, Vocativo -i, y / -owie, Acusat. -y, Genitivo -ów, Dativo -om, Instrumental -ami, Locativo -ach.

2. La clase femenina de tema en vocal $-a$.

3. La clase femenina de tema en consonante (vestigio de la antigua declinación en -i).

Ésta es la estructura básica que presentan sistemas como el ruso, bielorruso, ucraniano, polaco, bajo sorabo, serbocroata y esloveno. Sin embargo, en algunos sistemas, la tendencia a la reducción de la variedad flexiva alcanza su culminación cuando limita a dos macroclases flexivas el número de paradigmas netamente distintos: tal es el caso que nos muestran el alto sorabo y el casubo.

1. La clase masc.-neutra de tema en consonante (con las habituales diferencias de nominativo y acusativo).

2. La clase femenina, que integra los sustantivos femeninos de tema en consonante en la variante palatalizada de la única declinación femenina de que disponen.

Desde la perspectiva morfológica, el análisis de la lengua casuba muestra una clasificación de la flexión en dos macroclases, teniendo en cuenta que debido a la gramaticalización de la animicidad o del subgénero viril, la macroclase de masculino y neutro presenta dos variantes:

I. La clase masculina-neutra:

a) variante inanimada. Nominativo - Acusativo sg.: $(-\varnothing,-o)^{4}$.

Nominativo - Acusativo pl.: $(-i /-y,-a)$

b) variante animada. Acusativo - Genitivo sg.: $(-a)$

Acusativo - Genitivo pl.: (-ów)

II. La clase femenina: Genit. sg - Nom., Acus. pl.: $(-i /-y)$

Dativo - Locativo sg.: (-e)

Finalmente, la lengua casuba, como el resto de las lenguas eslavas, sigue diferenciando los sustantivos palatalizados (temas en -jo, -ja ) de sus correlatos no palatalizados. El sistema conserva casi al completo las correspondencias morfofonoló-

\footnotetext{
3 Empleamos el término "fusión" para referirnos a la redistribución de las desinencias entre dos clases flexivas que desemboca en la configuración de un paradigma mixto desde el punto de vista etimológico, conformado por terminaciones de una y otra procedencia.

${ }^{4}$ La evolución del sistema nominal eslavo afecta igualmente a la estructura de oposiciones y sincretismos paradigmáticos: synemptoseis o coincidencias materiales entre casos (MEISER 1992: 190).
} 
gicas del eslavo común, con alguna excepción (en aquellos sustantivos terminados en velar) que destacaremos oportunamente.

\section{Los sustantivos masculinos. Desinencias regulares}

Conforme a lo expuesto anteriormente, la caracterización morfológica de la flexión de los sustantivos masculinos en la lengua casuba responde a los siguientes criterios:

a) sustantivos masculinos animados acabados en consonante dura/ no palatalizada (excepto $k, g, r$ ). Ej.: chlop "hombre".

Polaco: SG. Nom. chtop - $\varnothing$, Voc. $-u$, Acu. $-a$, Gen. $-a$, Dat. -owi, Instr. -em, Loc. -e.

PL. Nom. chłop-i/-y/-owie, Voc. -i/-y/-owie, Acu. -ów, Gen.-ów, Dat. -om, Instr. -ami, Loc. -ach.

Casubo. SG. Nom. chłop - $\varnothing$, Voc. - 'e, Acu. - $a$, Gen. - $a$, Dat. -owi/-u, Instr. -em, Loc. -'e PL. Nom. chłop-i/-ë/-owie, Voc. -i, Acu. -ów, Gen. -ów, Dat. -om, Instr. -amil-ama, Loc. -ach.

b) sustantivos masculinos inanimados acabados en consonante dura/ no palatalizada (excepto $k, g, r$ ). Ej.: lës "bosque".

Polaco: SG. Nom. les - $\varnothing$, Voc. - $u$, Acu. - $\varnothing$, Gen. - $u$, Dat. -owi, Instr. -em, Loc. -e. PL. Nom. les $-y$, Voc. $-y$, Acu. $-y$, Gen. -ów, Dat. -om, Instr. -ami, Loc. -ach.

Casubo. SG. Nom. lës - $\varnothing$, Voc. - $-u$, Acu. - $\varnothing$, Gen. $-u /-\ddot{e}$, Dat. -owi, Instr. $-u$, Loc. - $u$. PL. Nom. lës -e, Voc. -e, Acu. -e, Gen. -ów, Dat. -om, Instr. -ami/-ama, Loc. -ach.

c) sustantivos masculinos acabados en $k, g, r$. Ej.: brzég 5 "orilla".

Polaco: SG. Nom. brzeg - $\varnothing$, Voc. $-u$, Acu. $-\varnothing$, Gen. $-a /-u$, Dat. -owi, Instr. -em, Loc. - $u$. PL. Nom. brzeg $-i /-y$, Voc. $-i /-y$, Acu. -i/-ów, Gen. -ów, Dat. -om, Instr. -ami, Loc. -ach.

Casubo. SG. Nom. brzég - $\varnothing$, Voc. brzeg -u, Acu. brzég - $\varnothing$, Gen. brzeg-a/-u, Dat. brzeg -owi, Instr. brzed '̇' -em, Loc. brzeg -u.

PL. Nom. brzed $\dot{z}-i$, Voc. brzed $-i$, Acu. brzed $\dot{z}-i$, Gen. brzeg -ów, Dat. -om, Instr. -ami/ama, Loc. -ach.

d) sustantivos masculinos animados acabados en consonante blanda/ palatalizada. Ej.: kóń "caballo".

Polaco: SG. Nom. koń - $\varnothing$, Voc. koni - $-u$, Acu. $-a$, Gen. $-a /-u$, Dat. -owi, Instr. -em, Loc. - $u$. PL. Nom. kon - $i$, Voc. - $i$, Acu. -e/-ów, Gen. -ów, Dat. -om, Instr. -ami, Loc. -ach.

Casubo. SG. Nom. kóń - $\varnothing$, Voc. kon’ - $u$, Acu. - $a$, Gen. - $a$, Dat. -u/-owi/-ewi, Instr. -em, Loc. $-u$.

\footnotetext{
5 é : vocal cerrada.

${ }^{6} o ́$ : vocal cerrada.
} 
PL. Nom. kon' -e, Voc. -e, Acu. -e, Gen. kon' -ów /-i, Dat. kon' -om, Instr. kon' -ami/ama, Loc. -ach.

e) sustantivos masculinos inanimados acabados en consonante blanda/ palatalizada. Ej.: kosz "cesta.

Polaco: SG. Nom. kosz -Ø, Voc. -u, Acu. -Ø, Gen. - $a$, Dat. -owi, Instr. -em, Loc. -u

PL. Nom. kosz -e, Voc. -e, Acu. -e, Gen. -ów, Dat. -om, Instr. -ami, Loc. -ach.

Casubo. SG. Nom. kosz -Ø, Voc. $-u$, Acu. $-\varnothing$, Gen. $-a$, Dat. $-u /-o w i$, Instr. -em, Loc. $-u$. PL. Nom. kosz -e, Voc. -e, Acu. -e, Gen. -ów/-i, Dat. -om, Instr. -ami/-ama, Loc. -ach.

Como se puede observar, los criterios que delimitan las distintas subclases flexivas en las declinación de los sustantivos masculinos de la lengua polaca coinciden con la clasificación establecida para la lengua casuba. La diferenciación entre sustantivos acabados en consonante palatalizada y no palatalizada se conserva en ambos sistemas, así como la distinción para aquéllos terminados en velar. Sin embargo, el paralelismo no parece tan claro en lo que se refiere al criterio de animicidad.

Al analizar la morfología flexiva del casubo desde el punto de vista de la animicidad, las gramáticas sincrónicas (BREZA 1981: 112) establecen una clasificación de los sustantivos masculinos que distingue simplemente entre animados e inanimados. En contraste, la peculiaridad de los sustantivos masculinos polacos radica en el hecho de que en las formas de nominativo plural se establece otra diferenciación siguiendo un criterio de virilidad: por un lado, los sustantivos animados viriles/ personales y, por otro, un grupo que incluye los inanimados pero también los sustantivos animados no viriles/ no personales (PRESA 2008).

El Nominativo Plural en la Lengua Polaca:

a) Temas en consonante dura (excepto $-\mathrm{k},-\mathrm{g}$ ):

Personal: Ej. SG.: student "estudiante" - PL.: studenci

No personal anim. Ej. SG.: kot "gato" - PL.: koty

e inanimados. Ej. SG.: dywan "sofá" - PL.: dywany

b) Temas en -k, -g:

Personal: Ej. SG.: Polak "polaco" - PL.: Polacy

No personal anim. Ej. SG.: ptak"pájaro - PL.: ptaki

e inanimados. Ej. SG.: pociag "tren" - PL.: pociagi

c) Temas en consonante blanda:

Personal: Ej. SG.: złodziej "ladrón" - PL.: złodziei

No personal anim. Ej. SG.: koń "caballo" - PL.: konie

e inanimados. Ej. SG.: pokój "habitación" - PL.: pokoje

d) Temas en consonante funcionalmente blanda:

Personal: Ej. SG.: lekarz "médico" - PL.: lekarzy

No personal anim. Ej. SG.:grzywacz "torcaz" - PL.: grzywacze

e inanimados. Ej. SG.:bagaż "equipaje" - PL.: bagaże 
En nuestra opinión, este rasgo de virilidad representa una característica innovadora e individual de las lenguas polaca y eslovaca, que no se observa en el casubo así como tampoco en la mayoría de las lenguas eslavas restantes.

\section{Rasgos diferenciadores en la declinación de los sustantivos masculinos}

4.1. En el genitivo singular de los sustantivos masculinos encontramos concurrencia entre las desinencias $-a y-u$. Esta característica, común a todas las lenguas eslavas, se justifica mediante la fusión de los tipos paradigmáticos antiguos de los temas en - $o$ y en - $u$ en eslavo común. La revisión de los datos más antiguos de las lenguas eslavas constata que la redistribución de las desinencias entre las dos clases flexivas mencionadas desembocó en la configuración de un paradigma mixto desde el punto de vista etimológico, conformado por terminaciones de una y otra procedencia. Esta fusión flexiva se produce esencialmente sobre la base de la categoría de género, lo que explica que la penetración de las formas de los temas en - $u$ en los temas en -o sea especialmente intensa, si bien no única, entre los sustantivos de género masculino.

La observación de los ejemplos en todas las lenguas eslavas indica que no existe un criterio específico que explique en su conjunto la selección de una u otra desinencia. No obstante, cuando permanece la concurrencia entre desinencias de distinto origen para un mismo caso, éstas acaban siendo sometidas a especialización gramatical. Así pues, parece no cuestionarse el principio generalizado por el cual los sustantivos masculinos animados presentan una tendencia a adoptar la desinencia $a$ (procedente de los temas en -o), mientras que los sustantivos masculinos inanimados seleccionan la desinencia $-u$ (de los antiguos temas en $-u$ ). Ej.: chtopa "del chico"; króla "del rey"; wilka "del lobo".

Por otra parte, debemos destacar como rasgo característico del casubo la aparición de la desinencia $-\ddot{e}$ en lugar de $-u$ para las terminaciones de genitivo singular, resultado que se explica a partir de la evolución fonética del sistema vocálico de la lengua casuba (ej.: lodë "de hielo"; miodë "de miel"; deszczë "de la lluvia"; stotë "de la mesa"; jedwabie "de seda).

4.2. En el dativo singular concurren las terminaciones -owi /-ewi y -u. Este fenómeno de nuevo se explica a partir de la fusión de los antiguos temas en - $o$ y en $-u$. En consecuencia, la desinencia orgánica $-u$ de los temas en - $o$ empieza a ser sustituida por -owi /-ewi de los temas en - $u$. Este proceso afecta inicialmente a los nombres de persona y después a los animados en general, finalmente acaba penetrando en el dominio de los inanimados. Su distribución, a primera vista, puede parecer impredecible, ya que no coincide con la de otras lenguas eslavas como, por ejemplo, el polaco (ej.: pol. królowi "para el rey", cas. królewi, królë; pol. stolarzu "para el carpintero", cas. stolarzewi; pol. koniu "para el caballo", cas. koniewi). A la luz de estos ejemplos se puede interpretar que el carácter innovador que presenta la lengua polaca en la aplicación de la desinencia $-u$ (de los temas en $-o$ ) en los sustantivos animados es compartido por la lengua casuba. Sin embargo, la innovación casuba 
debe interpretarse como una tendencia a la unificación generalizada de la desinencia -owi /-ewi en toda la clase flexiva, extendiéndose también a los sustantivos inanimados (ej. kôzan'owi "para el sermón"). Una formación desconocida para los neutros de la lengua polaca que demuestra, a su vez, que en la lengua casuba los paradigmas de los sustantivos masculinos y neutros pertenecen al mismo grupo flexivo.

Otro rasgo característico del casubo que debemos mencionar es la terminación owiu, de escasa productividad, pero no exenta de ejemplos: ksędzowiu "para el sacerdote". Su origen se explica a partir de una contaminación desinencial ${ }^{7}$ entre la marca antigua de los temas en $-u(-o v i)$ y la de los temas en -o $(-u)$. Este fenómeno, que aparece atestiguado en las terminaciones de dativo sg. -oju, -eju en el bajo sorabo, también se puede constatar en las desinencias -owu / -ewu del eslovincio occidental (LORENTZ 1958-62 y 1971, MAŃCZAK 1977).

En cuanto a la terminación $-u$ de dativo singular, al igual que ocurre en el genitivo singular $-u$, la consolidación de las vocales cerradas en el sistema fonético casubo hace que en las zonas del noreste encontremos la terminación $-\ddot{e}(<\breve{\mathrm{u}})$ en lugar de la esperada -u (ej.: psë "para el perro"; królë "para el rey").

Finalmente, como rasgo innovador de la lengua casuba en el ámbito eslavo debemos destacar la existencia de las terminaciones -оти /-ети procedentes del paradigma flexivo de los adjetivos (ej.: uczniomu /uczniemu "para el alumno"; koniomu/ koniemu "para el caballo"). Se trata de una formación claramente motivada por la analogía, si tenemos en cuenta la existencia del paradigma alternativo que presentan los sustantivos neutros, que adoptan las desinencias propias de los adjetivos en la formación de los casos oblicuos (ej.: polégo, polému, polim).

4.3. El instrumental singular presenta como forma generalizada las desinencias $-\mathrm{om} / \mathrm{-em}$, procedentes de la fusión de los temas en - $\mathrm{o}$ y $-u$, en un estadio cronológico anterior procedentes de los temas en - $O$.

No obstante, hemos centrado nuestra atención en la diversidad de variantes que nos presenta la lengua casuba con respecto a la terminación -em (ej. bokem, bokę, bociem, boczem; rogem, roge, rodziem, rodżem). En primer lugar comprobamos que en las áreas septentrionales de habla casuba se ha desarrollado una variante nasal -e a partir de la desinencia etimológica -em. En consecuencia, esta desinencia nasal constituye una innovación dentro la flexión nominal casuba, al tratarse de una creación posterior a la desinencia etimológica $-\mathrm{em}^{8}$. Por otra parte, las consonantes $k, g$, como en la mayoría de las lenguas eslavas, sufren el fenómeno de palatalización, pero en el casubo este fenómeno presenta un carácter innovador al desarrollar una palatalización de índole africada $(k>c i, g>d z i)$. Paralelamente, se ha desarrollado en época reciente un nuevo caso de innovación, por influjo de la lengua polaca (BREZA 1975, 33-37), mediante el cual la lengua casuba abandona sus propias formas de palatalización africada $(c i, d z i)$ sustituyéndolas por las formas de palatalización polacas $(c z, d \dot{z})$, de índole conservadora y comunes en todos los procesos de palatalización de las lenguas eslavas.

\footnotetext{
7 blending (StTONE, 1993 : 770).

${ }^{8}$ BREZA Y TREDER 1981: 114 "końcówka - e powstała $w$ wyniku rozwoju fonetycznego z -em".
} 
Por último, nos queda determinar si nos encontramos ante un fenómeno de palatalización tardía. En principio parece tratarse de un caso de alternancia entre las dos variantes $k / c i$ y $g / d z$, cuya distribución respondería a criterios geográficos: $k, g$, sin palatalizar caracterizarían las áreas septentrionales, mientras que $c i, d z$ estarían adscritas a las regiones del sur (URBAŃCZYK 1972).

Por consiguiente, conforme a los factores espacio-temporales que hemos argumentado anteriormente, resumimos la distribución de las variantes en el siguiente esquema:

Norte: bokem $>$ boke ; rogem $>$ roge

Sur: bociem > boczem; rodziem >rodżem

Ahora bien, si observamos con detenimiento los ejemplos que nos ofrece el paradigma de los sustantivos neutros, podemos comprobar que la palatalización de los sustantivos acabados en $-k,-g$ se manifiesta de manera regularizada en el ámbito de los neutros (ej.: ocziem, łóżcziem). A partir de este hecho podemos interpretar que no se trata de un fenómeno de palatalización tardía, pues no parece probable que tal innovación se haya impuesto únicamente entre los sustantivos neutros sin consolidarse primero entre los masculinos. Lo más natural es que el desplazamiento se haya producido desde los masculinos hacia los neutros. En consecuencia, resulta más lógico pensar que esta palatalización constituye un rasgo propio de la evolución de la lengua casuba (que también se extiende a los neutros) y que la realización no palatalizada que presentan los masculinos en las áreas septentrionales responde a una forma adoptada por influjo de la lengua polaca ${ }^{9}$.

4.4. En el locativo singular como forma generalizada prevalece la desinencia -e (procedente de los antiguos temas en -o, coincidiendo con las demás lenguas del ámbito eslavo) para los sustantivos acabados en consonante no palatalizada. Por otra parte, en el caso de los sustantivos acabados en consonante palatalizada se opta por las desinencias $-u /-\ddot{e}$ (procedente de los temas en $-u$ ) (POPOWSKA-TABORSKA 1961). El rasgo característico del casubo en cuanto a esta forma flexiva se manifiesta en los sustantivos acabados en $-s,-z$ que forman el locativo singular mediante la desinencia - $u$ (ej.: w lasu "en el bosque", na wozu "en el carro"). En contraste, encontramos la lengua polaca más innovadora en este aspecto, pues adopta la desinencia - $e$ de los antiguos temas en -o palatalizando a su vez la consonante precedente (ej.: w lesie "en el bosque", na wozie "en el carro"). La lengua casuba conserva la desinencia de los temas en - $u$ del eslavo común, coincidiendo en este rasgo con el carácter conservador de la lengua rusa (no siendo necesaria entonces la palatalización de la consonante precedente). Ante este hecho podemos interpretar que la escisión entre la lengua polaca y el casubo ya era palpable desde época prepolaca, pues en los tratados de gramática histórica de la lengua polaca se afirma que desde sus orígenes, en antiguo polaco, los sustantivos acabados en consonante dura/no palatalizada

\footnotetext{
9 BREZA 1981: 69 "Dlaczego mówi się na kaszubach słodcie, a nie słodkie [...] - Tu zmiękcza się w mowie $<<$ kigi $>>n a<<c i-d z i>>$. To podobno bardziej po polsku niż w ogóle po polsku”.
} 
(exceptuando $-k,-g,-c h$ ) adoptan de manera regularizada la desinencia $-e$ procedente de los antiguos temas en -o y sólo en dos ejemplos, citados habitualmente como excepciones (KLEMENSIEWICZ 1981: 274), aparece la desinencia $-u$ después de consonante dura ( synu "donde el hijo", $w$ domu "en casa").

Asimismo, la desinencia $-u$ (procedente de los antiguos temas en $-u$ ) es la forma más frecuente en la formación casuba del locativo singular de los sustantivos neutros acabados en consonante no palatalizada (ej.: na polu "en el campo"). Este hecho demuestra que el carácter conservador del casubo, en contraste con el polaco, se remonta a un estadio histórico de la lengua anterior al antiguo polaco y, además, constituye un rasgo consolidado de aplicación regular en todo este grupo flexivo conformado por los sustantivos masculinos y neutros.

4.5. El instrumental plural en -ama. Una vez suprimida la categoría del dual en el sistema nominal de las lenguas eslavas, existen todavía desinencias procedentes de ese paradigma que siguen desempeñando funciones gramaticales. La mayor parte de los restos formales del dual es reinterpretada en eslavo como morfología plural (remorfologización $)^{10}$. Las formas oblicuas de dual, fundamentalmente el dat.-instr., se conservan como marcas de plural en diversas lenguas y dialectos. Con respecto al grupo eslavo occidental ${ }^{11}$ en polaco también se observa en textos que datan de los s. XVI-XVII (ej.: palcóma, chłopóma, bratôma, konióma). Actualmente esta antigua forma no ha sobrevivido en el grueso de lenguas eslavas, pues se ha impuesto de manera regularizada la desinencia-ami, coincidente con la de los antiguos temas en $-\bar{a}$ (ROSPOND 2000). La pervivencia o resto del antiguo dual existente en el tronco común eslavo que la mayoría de las lenguas eslavas han perdido y que el casubo ha reinterpretado con forma de plural debe considerarse como una nueva forma de innovación del casubo.

\section{Los sustantivos neutros. Desinencias regulares}

La clasificación de los sustantivos neutros desde la perspectiva morfológica se establece en la lengua casuba conforme a los siguientes criterios:

a) sustantivos acabados en consonante no palatalizada (dura).

Ej.: pismo "carta".

Polaco: SG. Nom. pism-o, Voc. -o, Acu. -o, Gen. $-a$, Dat. $-u$, Instr. -em, Loc. -e.

PL. Nom. pism- $a$, Voc. - $a$, Acu. - $a$, Gen. - $\varnothing$, Dat. -om, Instr. -ami, Loc. -ach.

\footnotetext{
${ }^{10}$ La remorfologización indica bien la recuperación del valor morfológico por parte de un elemento flexivo previamente desmorfologizado, bien la alteración de la función morfológica que cumplía con anterioridad al cambio ese elemento flexivo, en cuyo caso cabe denominarla transmorfologización. En GREENBERG 1991: 301 esta reinterpretación de un segmento en una nueva función se identifica como regramaticalización. En LASS 1990 se denomina exaptación.

${ }^{11}$ En checo a partir del s. XVII se extiende entre los sustantivos masculinos las desinencia de instrumental plural -ama. Ej.: stromama, zubama (PUŠKAR 1970: 16, 43).
} 
Casubo. SG. Nom. pism-o, Voc. $-o$, Acu. $-o$, Gen. $-a$, Dat. $-u$, Instr. $-e m$, Loc. $-e$. PL. Nom. pism-a, Voc. - $a$, Acu. -a, Gen. -ów, Dat. -om, Instr. -ami/-ama, Loc. -ach.

b) sustantivos acabados en consonante palatalizada (blanda).

Ej.: sërce "corazón".

Polaco: SG. Nom. serc-e, Voc. $-e$, Acu. $-e$, Gen. $-a$, Dat. $-u$, Instr. $-e m$, Loc. $-u$. PL. Nom. serc- $a$, Voc. $-a$, Acu. $-a$, Gen. $-\varnothing$, Dat. -om, Instr. -ami, Loc. -ach.

Casubo. SG. Nom. sërc-e, Voc. $-e$, Acu. $-e$, Gen. $-a$, Dat. $-u$, Instr. -em, Loc. $-u$. PL. Nom. sërc-a, Voc. - $a$, Acu. - $a$, Gen. -ów, Dat. -om, Instr. -ami/-ama, Loc. -ach.

c) sustantivos acabados en -é. Ej.: kôzané "sermón".

Polaco: SG. Nom. kazani -e, Voc. -e, Acu. -e, Gen. $-a$, Dat. $-u$, Instr. -em, Loc. $-u$. PL. Nom. kazani $-a$, Voc. $-a$, Acu. $-a$, Gen. $-\varnothing$, Dat. -om, Instr. -ami, Loc. -ach.

Casubo. SG. Nom. kôzan -é, Voc. -é Acu. -é, Gen. -a/-u/-i/-ô/-ego, Dat. -u/-ewi/ému, Instr. -em, Loc. $-u$-im.

PL. Nom. kôzan -a, Voc. - $a$, Acu. -a, Gen. -ów, Dat. -om, Instr. -ami/-ama, Loc. -ach.

d) sustantivos acabados en nasal - e. Ej.: cele "becerro".

Polaco: SG. Nom. ciel -e, Voc. $-e$, Acu. $-e$, Gen. $-e t-a$, Dat. $-e ̨ t-u$, Instr. $-e ̨ t-e m$, Loc. $-e ̨ t-u$. PL. Nom. ciel -ęt-a, Voc. -ęt-a, Acu. -ęt-a, Gen. -ęt- $\emptyset$, Dat. -ęt-om, Instr. -ęt-ami, Loc. -ęt-ach.

Casubo. SG. Nom. $c e l-e$, Voc. $-e$, Acu. $-e$, Gen. $-e c-a$, Dat. $-e c-u$, Instr. -ęc-em, Loc. $-e ̨ c-u$.

PL. Nom. $c e l-e ̨ c-a$, Voc. -ęc-a, Acu. -ęc-a, Gen. -ęc-ów, Dat. -ęc-om, Instr. -ęc-ami, Loc. $-e c-a c h$.

\section{Rasgos diferenciadores de los sustantivos neutros}

En general, las particularidades que presenta el paradigma de los neutros ya han sido expuestas anteriormente por su coincidencia con los sustantivos masculinos. Nos referimos a características tales como las formaciones en -owi del dativo singular o las formaciones en $-u$ del locativo singular. Desinencias que, como hemos explicado, deben su origen a la fusión de los antiguos temas eslavos en -o y $-u$. Su evolución, aunque debería haber sido exclusiva de los sustantivos masculinos, en casubo se ha extendido también a los neutros. De este modo, hemos justificado nuestro planteamiento al analizar los sustantivos masculinos y neutros dentro de la misma macroclase flexiva. Esta condición de convergencia entre ambos géneros constituye para nuestra hipótesis un argumento sólido a la hora de situar la línea de evolución histórica de la lengua casuba en un estadio cronológicamente paralelo a la formación de la lengua polaca. 
Por otra parte, en la declinación de los neutros debemos destacar la formación del genitivo plural, donde encontramos el empleo de la desinencia -ów, en lugar de la propiamente neutra -ø (LORENTZ 1958-62:905; STONE 1993:771). En consecuencia este rasgo nos aleja de la declinación polaca y refuerza nuestro planteamiento al incluir los sustantivos masculinos y neutros dentro de la misma macroclase flexiva. Dentro de este mismo planteamiento también encontramos el uso de la antigua desinencia de dual -ama en las formas de dativo, en convergencia con los sustantivos masculinos.

Finalmente, debemos destacar la doble realización paradigmática que presentan algunos neutros acabados en -é $(<-\bar{e})$, que pueden adoptar en singular las desinencias adquiridas de la declinación adjetival. Consideramos que se trata, sin duda, de un caso de contaminación sin consecuencias determinantes para nuestro estudio. No obstante, nos ha parecido conveniente señalarlo por su originalidad dentro del sistema, pues además justifican las variantes -ému, -im que encontramos en las formas de dativo y locativo singular de los temas en $-e ́$.

Flexión de este tipo de sustantivos neutros en singular: polé "campo"

Variante A (des. Nominales): Nom. pol -é, Voc. -é, Acu. -é, Gen. -al -ô, Dat. -u/-owi, Instr. $-e$ /-em, Loc. $-u$.

Variante B (des. Adjetivales): Nom. pol -é, Voc. -é, Acu. -é, Gen. -égo, Dat. -ému, Instr. -im, Loc. -im.

\section{Conclusiones}

En el presente trabajo hemos analizado el material morfológico del casubo, limitándonos únicamente al sistema nominal de los sustantivos masculinos y neutros. Nuestra investigación, al abordar la perspectiva diacrónica principalmente, presenta detalladamente aquellos cambios formales acontecidos exclusivamente en la lengua casuba desde sus orígenes en el ámbito del eslavo común. Estos datos, reforzados mediante la comparación con los sistemas flexivos polacos, elegidos por su relación de proximidad geográfica, nos han proporcionado argumentos lingüísticos suficientes para determinar las principales tendencias que se observan en la evolución de la lengua casuba.

A partir de los resultados obtenidos hemos comprobado que no existe un criterio específico y uniforme que explique en su conjunto la orientación adoptada por la lengua casuba en el desarrollo de sus cambios flexivos. Hemos encontrado, por un lado, rasgos morfológicos que responden a una actitud conservadora de la lengua, pero, por otro lado, el análisis de los sustantivos casubos también nos ha proporcionado suficientes elementos innovadores que nos permiten identificar la hipotética orientación de los cambios lingüísticos casubos en una línea de evolución de tendencia innovadora. Esta afirmación se justifica al contrastar la cantidad de rasgos conservadores encontrados con el grueso de innovaciones resultantes de nuestra 
investigación. Sólo el cómputo total de los fenómenos morfológicos conforme apunten en una u otra dirección nos permitirá atestiguar la tendencia de la evolución flexiva en la lengua casuba.

En el presente trabajo, desde la perspectiva conservadora, hemos hallado los siguientes rasgos:

La lengua casuba, en la formación del locativo sg., sigue manteniendo la desinencia $-u /-\ddot{e}$ (procedente de los antiguos temas en $-u$ ) coincidiendo con las desinencias que encontramos en otras lenguas eslavas. En constraste, la lengua polaca, más innovadora, extiende la desinencia -e (de los temas en -o) palatalizando la consonante precedente (ej. pol. w lesie "en el bosque", cas. w lasu). Estas formas polacas en -e ya aparecen, según los tratados de gramática histórica de la lengua polaca, en antiguo polaco. Este hecho podría apuntar a la escisión entre la lengua polaca y el casubo en un estadio históricamente anterior a la formación del antiguo polaco.

La pervivencia de la antigua forma de dual -ama, reinterpretada como desinencia de instrumental plural, constituye un importante indicio del carácter conservador del casubo, en contraste con la casi totalidad de las lenguas eslavas que han simplificado su paradigma adoptando la antigua forma -ami como única desinencia en la formación del instrumental plural. A pesar de la reinterpretación de índole semántica como forma de plural, no podemos considerar este rasgo como una innovación plena del casubo ya que en textos polacos que datan de los s. XVI-XVII también encontramos estas variantes como formas de plural (ej. palcóma "con los dedos", bratôma "con los hermanos", konióma "con los caballos"). Sin embargo, éstas en la lengua polaca no sobrevivieron y acabaron imponiéndose de manera regularizada las formas en -ami.

Por otra parte, el carácter innovador del casubo se manifiesta en la constatación de los siguientes rasgos:

En primer lugar, debemos referirnos a la estructura básica que presentan los sistemas de la flexión nominal en el grueso de las lenguas eslavas (ruso, bielorruso, ucraniano, polaco, bajo sorabo, serbocroata y esloveno). Estas lenguas distribuyen la flexión nominal de sus sustantivos en base a tres macroclases flexivas. Sin embargo, en alto sorabo y en casubo reduce esta variedad limitando a dos macroclases el número de sus paradigmas (la clase masculina-neutra y la clase femenina). Este hecho se puede considerar el primer rasgo de innovación morfológica que encontramos en el estudio de la flexión nominal casuba y nos adelanta la orientación innovadora e independiente que va a caracterizar el desarrollo de los sistemas morfológicos casubos.

En la forma de dativo sg. de los sustantivos neutros es frecuente el empleo de la desinencia -owi, una formación desconocida en los neutros de la lengua polaca. Esta innovación, por tanto, confirma que en la lengua casuba los paradigmas de los sustantivos masculinos y neutros pertenecen al mismo grupo flexivo. Asimismo, la existencia de las formas en -owiu, también aplicadas al dativo sg. casubo, consecuencia de una contaminación desinencial entre la marca antigua de los temas en - $u$ $(-o v i)$ y la de los temas en -o (-u), atestiguada en las terminaciones de dativo sg. del bajo sorabo, constata la tendencia innovadora de la lengua casuba en este aspecto. 
El desarrollo de la desinencia etimológica de instrumental sg. -em, presenta en casubo una variante nasal -e, de creación evidentemente posterior, que vuelve a corroborar la evolución de esta lengua en una línea indudablemente innovadora. Asimismo, debemos añadir el fenómeno de palatalización africada que se observa en la formación del instrumental sg. de los sustantivos acabados en velar $(k>c i ; g>$ $d z i$ ). Esta circunstancia, que no se observa en ninguna de las lenguas eslavas, constituye, sin lugar a dudas, un nuevo rasgo que confirma la individualidad del casubo y su originalidad fonética y morfológica (ej. pol. bokiem "por el lado", rogiem "por la esquina"; cas. bokę/ bociem, rogę/ rodziem).

Con respecto a la declinación de los sustantivos neutros, destacamos la generalización de la desinencia -ów, en lugar de la propiamente neutra - $\varnothing$, en las formas de genitivo sg. Este rasgo que vuelve a alejarnos de la declinación polaca, representa una nueva iniciativa de índole innovadora dentro de la morfología casuba y refuerza nuestra hipótesis que incluye los sustantivos y neutros dentro de la misma macroclase flexiva.

El inventario de características gramaticales que hemos señalado en nuestro análisis pone de manifiesto la primacía que adquiere el conjunto de rasgos innovadores que posee el casubo sobre los rasgos conservadores. En conclusión, podemos determinar que las líneas de evolución desarrolladas en la historia de la lengua casuba se alejan una y otra vez del polaco hacia tendencias innovadoras que confieren a nuestra lengua de estudio una identidad y autonomía propias dentro del grupo lejítico de las lenguas eslavas. Quedan, no obstante, abiertas nuevas líneas de investigación que completen el estudio de todos los sistemas flexivos de la lengua casuba y que esperamos desarrollar en futuros trabajos.

\section{Referencias bibliográficas}

AJK=Atlas językowego kaszubszczyzny i dialektów sąsiednich T. I-XV, (1964-1978): (Z. Stieber (vols. I-VI) y H. Popowska-Taborska (vols. VII-XV) eds.), ZS Zakład Słowianoznawstwa PAN, Ossolineum, Wrocław.

BREZA, E. (1975): “Granice dialektu kaszubskiego w przeszłości i obecnie”, Pomerania XII, , nr 3, ZK-P Zrzeszenie Kaszubsko-Pomorskie, Gdańsk, 33-37.

BREZA, E. TREDER, J. 1999 [1981]: Gramatyka kaszubska, ZK-P Zrzeszenie KaszubskoPomorskie, Gdańsk.

CARSTAIRS, A. (1987): Allomorphy in Inflexion, Crom Helm, London-NewYork-Sydney.

GREENBERG, J.H. (1991): "The Last Stages of Grammatical Elements: Constractive and Expansive Desemanticization" en Approaches to Grammaticalization. I. Focus on Theoretical and Methodological Issues, 301-314, (E.C. Traugott, B. Heine eds.) John Benjamins, Amsterdam-Philadelphia.

KLEMENSIEWICZ, Z., LEHR-SPŁAWIŃSKI, T. y URBAŃCZYK, S. (1981): Gramatyka historyczna języka polskiego, PWN, Warszawa.

LASS, R. (1990): "How to do things with junk: exaptation in language evolution", Journal of Linguistics 26, 79-102.

LORENTZ, F. (1958-1962 [1927-1937]): Gramatyka pomorska, 2 vols., Instytut ZachodnioSłowiański, Ossolineum,Wrocław.

LORENTZ, F. (1971 [1919]) Kaschubische Grammatik, Hildesheim. 
MAŃCZAK, W. (1977): Stowiańska fonetyka historyczna a frekwncja, Uniwersytet Jagielloński, Kraków.

MEISER, G. (1992): "Syncretism in Indo-European languages - motives, process and results", TPhS Transaction of the Philological Society 90/2, 187-218.

POPOWSKA-TABORSKA, H. (1961): "Centralne zagadnienia wokalizmu kaszubskiego", Rocznik Gdański XXI, 339-343.

PRESA GONZÁLEZ, F. (2008): Gramática Polaca, Ediciones Cátedra, Madrid.

PUŠKAR, M. (1970): Istorična morfologija čes 'koï movi. Vidmina imen, 16-43, L'viv.

ROSPOND, S. (2000): Gramatyka historyczna języka polskiego, PWN, Warszawa-Wrocław.

STONE, G. (2001 [1993]): "Cassubian" en The Slavonic Languages, (B. Comrie y G.G. Corbett eds.), Routledge, London \& New York, 759-794.

URBAŃCZYK, S. (1972): Zarys dialektologii polskiej, PWN, wyd.4., Warszawa. 